\title{
Littermates and guesstimates
}

\section{Barry Cox \& Michael Stoddart}

The Mammalian Radiations: An Analysis of Trends in Evolution, Adaptation, and Behaviour. By John F. Eisenberg. Pp.610. US ISBN 0-226-19537-6; UK ISBN 0-485-30008-7. (Chicago University Press/ Athlone: 1981.) $\$ 45, £ 32$.

THE theme of John Eisenberg's book is the relationship between three aspects of mammals: their anatomy and physiology, the way in which they exploit their different habitats, and their behaviour and social structure. Clearly, these aspects must be integrated in any species, but Eisenberg goes further in attempting to compare the patterns of integration in different mammalian groups, and to suggest general trends that extend from one group to another.

The first 74 pages deal with the relationship between the areas of origin of the different groups and the changing continental configurations, and survey what Eisenberg calls "the early radiations" - monotremes, marsupials, edentates and lemurs. In the next 150 pages he deals with the remaining orders of mammal in similar fashion. $\mathrm{He}$ is at his least authoritative in the historical and taxonomic section, for he shows the Marsupialia as already in existence in the Lower Cretaceous, while the suggestion that monotremes evolved from multituberculates that reached Australia is to found one highly dubious hypothesis upon another. After uniting the South American ungulates with such African forms as elephants, Eisenberg notes that this suggests that they had a common ancestor in those areas before the two continents separated - though the separation took place in the midCretaceous, long before the differentiation of the ungulate eutherians. Furthermore, are the marsupials and edentates simply part of an "early radiation" of mammals? Since Eisenberg is attempting to deduce phyletic trees of behavioural traits, and these trees are in turn founded upon the classification and history derived from morphological studies of fossil and living forms, it is essential that he is accurate in these fundamental assumptions.

Eisenberg's method and assumptions are clearly explained on p.12.

From the initial radiations, there are today some living mammals, mostly in the tropics, that in many morphological features show relatively little modification from the original stocks . . it seems legitimate to infer that certain morphologically conservative species inhabiting niches in the tropics represent forms that are in a sense adapted to a 'conservative niche'. Thus a phylogenetic reconstruction of mammalian behavioural evolution should start with generalizations developed by comparing morphologically conservative forms that occupy what might be considered the niches of the Paleocene.

He goes on to comment (p.42) that "The age of the edentate and pholidote lineages allows them to serve as a basis for comparison with the remaining radiations of the eutherians". Finally (p.49)

If the Edentata are among the most primitive living eutherians, then the behaviour of a 'conservative' dasypodid such as Euphractus has great significance for comparisons with other morphologically conservative mammals. Unfortunately we have virtually no field data .... We must therefore rely heavily on captive studies.

The gaps in this chain of reasoning are obvious. To what extent is any niche today equivalent to a niche in the Palaeocene? Are armadillos really morphologically conservative? If they are, at least in those characters that condition their ecological niche, to what extent does this allow us to deduce that they are also conservative in their reproductive and behavioural strategies? How much meaning is there in the concept of a "phylogenetic reconstruction of mammalian behavioural evolution'? These are important reservations, that must be raised now because they counsel caution in reading the rest of the book.

In Chapters 17-23, Eisenberg discusses what he terms "macrophysiology and adaptation" - an integration of dietary specializations and ways of life. This is the classical stuff of mammalian adaptive radiation, and his approach is useful and thought-provoking. For example, why are fossorial niches incompletely occupied in the tropics, and why are more "macroniches" filled in North America than in Europe or North Asia?

In the final 100 pages of text, Eisenberg develops the theme that there was originally a common basic mammalian behavioural repertoire, which has been adapted through natural selection in the various diversifying lineages. He first attempts to identify this repertoire by comparing various patterns of behaviour in terrestrial mammals; this chapter is brief and rather unsatisfactory. However, in a detailed and most valuable analysis of social organization, Eisenberg spiritedly tries to correlate such behavioural systems as mating, rearing, foraging and refuging. $\mathrm{He}$ then extends his net to show relationships between demographic, ecological and sociological variables in a wide range of species. The use of arbitrary numerical values for qualitative characteristics (e.g. "reproductive rate" is scored from 1 to 7 ) is understandable but can be misleading. Many species vary their reproductive output and adopt a slightly different social organization at different altitudes or latitudes, so the reader must beware of these oversimplifications. However, the author seems more at home in this section than in the earlier parts of the book, and his extrapolations should fuel many a coffee-room debate.

There is an excellent and wide-ranging bibliography of over 1,700 references, and Eisenberg has had the happy idea of entering many of these in group versus subject tables that show, for example, references on rhinoceros behaviour or tapir ecology. Appendices, classifications of extant mammals and an index complete the book.

For research workers and postgraduate students this is certainly a stimulating book, full of data, correlations, extrapolations and provocative guesses. It is therefore dangerous material for the unwary or inexperienced, who may be unaware of the fundamental assumptions that Eisenberg's thesis is founded upon, and may be slow to appreciate the boundaries between correlation, extrapolation and guesswork.

Barry Cox is a Professor and Michael Stoddart a Lecturer in the Department of Zoology, King's College, University of London.

\section{Life of the long-haired stars}

\section{David W. Hughes}

Introduction to Comets. By John C. Brandt and Robert D. Chapman. Pp.246. ISBN 0-521-23906-0. (Cambridge University Press: 1982.) $£ 21, \$ 45$.

Comets are heavenly bodies of considerable beauty, volatile character and deep physical and chemical significance. Their contents are fresh, thermally unaltered and undifferentiated, and the large outpourings of gas and dust that occur when the comet is close to the Sun often produce a coma and tail of truly astronomical proportion. Comets are also newsworthy. The past decade has seen the blossoming of ultraviolet and infrared comet research; the next will see the launching of the first spacecraft designed to pass through the head of a comet and to gather in situ data.

Monographs on comets are scarce and there have been only three major ones since the turn of the century: G.F. Chambers's The Story of the Comets (Oxford University Press, 1910); R.A. Lyttleton's The Comets and their Origin (Cambridge University Press, 1953); and N.B. Richter's The Nature of Comets (Methuen, 1964 an enlarged translation of his 1954 book, Statistik und Physik der Kometen). We 